\title{
Advice for Parents on Advertisement's Effect on Children
}

\author{
Xiaomo $\mathrm{Hou}^{1, *}$ \\ ${ }^{1}$ University of California, Davis, Davis, California, United States 95616 \\ *Corresponding author. Email: axmhou@ucdavis.edu
}

\begin{abstract}
This paper investigates mass media advertising's negative effect on young children. As technology and internet are evolving in a faster pace than expected, it is important to take a step back to understand how people's lifestyle and decision-making method has changed accordingly. Furthermore, people need to reflect more on how these changes are impacting young children's appetite behavior. The paper focuses on analyzing children around the age of 7 . While there are some benefits that come with advertising, its negative effects like an increase in obesity are undeniable. The paper aims to analyze the issue first from historical background and then focuses on explaining what parents can do to minimize this effect on their children.
\end{abstract}

Keywords: advertising, children, behavioral influence, decision-making, television watching

\section{INTRODUCTION}

As social media and the internet keep on rising, people are becoming oblivious to the influence of watching television on young children. These younger generations are being targeted by many commercial companies because of children's influence on their family's purchasing decision and their potential financial value. More importantly, many companies believe that compared to adults, children are more of a vulnerable audience because they are easily influenced by commercials on television.

China has the largest population of children in the world. Children under the age of 15 have already mounted to 257 million in 2008 [2]. One characteristic about children in China is that they typically do not have any siblings which are beneficial for many commercial companies from an economic standpoint. Parents and family members will devote every resource to this one child since no one else is dividing their psychological attention as well as financial attention.

With rapid globalization and commercialization, media and advertising are able to follow closely with everyone's purchasing habits through big data, making it easier for large corporations to modulate their business plan in order to make more money. Someone might even say that "this process has created an unparalleled opportunity to develop a new generation of consumers"
(Chan, 2014 [2]). Researchers and primary caregivers should also evolve with time and make the right decision when children are encountered with innumerable commercials from both the online environment and television watching. Much research has already been done in this field, including how children's choice of diet can change due to the influence of advertising consumption, as well as the relationship between watching advertisements and children's wellbeing and life satisfaction.

This paper aims to explain why parents should begin to pay attention to the learning environment of their children and what they can do as a guide for their children to minimize the negative influence brought by the world of uproaring media.

\section{HISTORY OF ADVERTISING}

The earliest history of advertising can be traced back to a carving from Ancient Egyptians in 2000 BC. In 1704, the newspaper era rushed into the United States, but the changes in consumer behavior start only in the early 1900s when television and radio are taking all over newspapers in the U.S. The invention of television brings consumers closer to the product itself by speaking to the customers directly on a screen. Television made advertising even more personalized for its viewers. The "Golden Ages of Advertising" is marked during the 1960 s to the late 1980 s. Even though the tension was 
high during the Cold War, it does not stop the Americans from opening up their wallets. Many big companies started to create faces that represent their products, for example, the famous tiger created for Frosted Flakes that are still printed on the cereal box from the 21 st century.

\subsection{From Television to Internet Era}

The next major shift of advertising method was from television to the internet. With the raising of the internet and many websites published online, companies have even more control over what they want their consumers to see and to click on. In the beginning, companies learned to lure customers into clicking into an advertisement on a website which will lead to the purchasing page. Instead of advertising products, online advertising is more about learning consumers' behavior and finding out patterns in order to catch their attention. In the 21 st century, as big data is getting more and more into our daily lives, more accurate and precisely targeted advertisings are popping up in between your social media feeds. As a result, these little, small changes are everything that influences people's purchasing behavior. Nonetheless, with the accurate data source, companies and corporations can deliver products in front of their customers and tailored these ad styles to their individual preferences. In some ways, this new form of advertising is actually doing consumers some favors because they can just sit at home and scroll through their social media to get the perfect product delivered to their house. On the other hand, it also remedies lots of time where advertising companies used to spend on creating large campaigns in order to reach out to their consumers. For 7 years old children, advertising can also be somewhat beneficial: advertising exposure has a positive effect on personal growth. According to Suzanna J. Opree and Moniek Buijzen's research, advertisement on television that appeals fantasy and imagination can stimulate daydreaming for children. As a result, it "increases children's contemplation about future opportunities", which can lead to a purpose in life [4].

However, these changes are a two-sided blade that could potentially be very dangerous for children under 7 years old because they are unable to detect a persuasive message from those advertisements; therefore, fall for the online campaigns. Such inability is not necessarily a harmful threat if the television ad is about toys; however, it could potentially be harmful when it comes to alcohol and smoking, or even food choices.

\subsection{Longitudinal Study on Children's Consumption Behavior}

Some research shows concerns about children who watch lots of advertising are more likely to have higher food calories intake. In other words, they are eating less healthy compared to those children who consume fewer television shows. Between 2006 to 2009, Potvin Kent and Wanless conducted a study on the changes in children's food choices after exposure to food advertising on television in Canada. Their research shows that the relationship between food marketing and obesity in children is positively related.

The research is a longitudinal study where data was collected from 2006 to 2009 and again in 2011 to see if there are any changes. The researchers purchased data for the month of May because they want to avoid any possible inflated advertising budgets during holiday seasons. From the 2006-2009 exposure, "snacks and yogurt increased significantly for both sample sites and the average number of fast food advertisements seen by children in Toronto increase from 40-52 advertisements per month" [5]. Clearly, companies are not willing to take a step back in their advertising game.

Table 1. Average number of spots viewed by 2-11year-olds per month on all stations 2006, 2009 and percentage change between 2006-2009

\begin{tabular}{|c|c|c|c|c|c|c|}
\hline \multirow[t]{2}{*}{ Food category } & \multicolumn{3}{|c|}{ Toronto } & \multicolumn{3}{|c|}{ Vancouver } \\
\hline & $\begin{array}{l}\text { May } \\
2006\end{array}$ & $\begin{array}{l}\text { May } \\
2009\end{array}$ & $\begin{array}{c}\% \\
\text { Change }\end{array}$ & $\begin{array}{l}\text { May } \\
2006\end{array}$ & $\begin{array}{l}\text { May } \\
2009\end{array}$ & $\begin{array}{c}\% \\
\text { Change }\end{array}$ \\
\hline Snacks & 7.2 & 28.0 & 288.9 & 4.7 & 16.2 & 244.7 \\
\hline Cheese & 9.6 & 8.6 & -10.4 & 7.3 & 7.0 & -4.1 \\
\hline Yogurt & 2.2 & 5.0 & 127.3 & 1.4 & 5.0 & 257.1 \\
\hline Cereals & 36.9 & 32.5 & -11.9 & 20.7 & 19.0 & -8.2 \\
\hline Juices & 12.3 & 4.6 & -62.6 & 9.3 & 4.5 & -51.6 \\
\hline Soft drinks & 4.5 & 2.8 & -37.8 & 2.7 & 3.0 & 11.1 \\
\hline $\begin{array}{l}\text { Diet soft } \\
\text { drinks }\end{array}$ & 3.8 & 2.5 & -34.2 & 3.9 & 1.5 & -61.5 \\
\hline Fast food & $39.9^{\mathrm{a}}$ & $52.0^{\mathrm{a}}$ & 30. & $37.4^{\mathrm{a}}$ & $36.8^{\mathrm{a}}$ & -1.6 \\
\hline Total & 116.4 & 136 & 16.8 & 87.4 & 93.0 & 6.4 \\
\hline
\end{tabular}

Perhaps with some decrease in soft drinks and juices, but the overall calories of those advertised food remained high. And in 2011, research by Potvin Kent and Wanless (2014) suggests that the total exposure was highest for fast food, cheese, and chocolate bars on all stations as well as on children's specialty channels in both Toronto and Vancouver. Children are being more aggressively marketed on children's specialty channels. Potvin Kent and Wanless (2014) conclude that some government regulations need to be implemented to ensure that children's minimum nutritional standards are being met on those advertisements.

They further elaborate that fast food companies should all pledge to stop direct advertising to children under 12 years on multiple media platforms. If children are seeing less nutritional food on screen for the majority of time, it will eventually influence their food preference. Parents will experience a harder time getting their children to adopt a healthier food choice. Other than food choice, youth exposure to alcohol and tobacco will also result in unhealthy consequences. 
Although tobacco marketing has been banned from television, "youth exposure to television advertising for electronic cigarettes doubled from 2011 to 2013" [3]. Lapierre et al. (2017) suggest that children who are not fully equipped with the theory of mind will have trouble understanding selling intent and the social symbolism of brands. Therefore, effective actions are needed from primary caregivers in order to prevent children from negative effects under the influences of advertising. This article will explain some basic intervention parents should start to do and it will function as a guide for parents and primary caregivers to take better care of their children. Before understanding how to strengthen children's competencies to face persuasive information on advertisements, it is important to investigate the process which determines how advertising affects children's judgment and decision making [1].

A dual-step and dual-process perspective was adopted by Büttner et al. (2013) to make sure that they were able to get a better understanding of the creation of memory structure as well as the influence of memory structure in purchasing and consumption situations [1]. The influence of advertisement lasts longer than the message itself. It continues to affect children's consumption and purchasing behaviors after the ad exposure. Therefore, the dual process allows the researchers to detect explicit and implicit processes. Explicit refers to advertising effects that can be detected and monitored with raw eyes, while implicit processes usually involve unconscious and automatic behaviors.

\section{ANALYSIS/RECOMMENDATION}

To combat the implicit processes, parents should encourage their children to self-regulate or take selfcontrol by reminding them what food is unhealthy or pointing out the harmful information found in advertisements. Büttner et al. (2013) found that selfregulation is a first step to prevent undesired effects of advertising on behavior. The key to such regulation is the association between thinking about a temptation (e.g. drinking coke) and the activation of self-control. In other words, when children want to buy soft drinks, they automatically trigger a relevant self-control goal (e.g. drinking water). Parents should act like reinforcers or guidance to remind their children of what temptation to avoid. Instead of practicing self-control, parents can also guide their children to focus on something else to resist the temptation of watching ads. By redirecting children's focus to alternative goals and narrowing down goals, these products from ads can mean less valuable to children.

Furthermore, parents or caregivers can practice such techniques with their children in many places, even away from television. For instance, before going into the mall, parents can prompt their children to find a specific product (e.g. orange juice) in order to minimize other stimuli in a mall setting. With a focus in mind, children are less likely to be distracted by big posters advertising for toys. Depending on the individual family, these techniques can vary. For example, some families might let their children choose that specific goal to look for, but other families might be more protective and set the goal for their kids [1].

Regulation for advertisement can also play an important role to effectively reduce negative influence on children. If government requires all advertising with manipulative content to include a forewarning, children will become more skeptical towards the advertainment [6]. As a result, it reduces children's desire for the product advertised. Parents can also adopt such finding by warning their children of advertising's manipulative intent when watching television. It is sufficient to “activate children's attitudinal advertising literacy and lower their advertised product desire" [6]. Parents need to take effective actions to help their children to process information from television as well as the internet. Banning their children from television watching is not ideal nor effective.

\section{CONCLUSION}

This paper demonstrates that advertisements can subconsciously influence children's decision-making and behavior. Parents and caregivers do play a prominent role to make children more resistant towards advertising's manipulation. External and internal processes can work hand in hand to help children to cope with persuasive information. Parents can act as guidance and forewarn children the potential manipulative information from advertisement. This paper does contain certain limitations. The longitudinal study was done only in Canada; therefore, a situation in the U.S. could somewhat be different. Further research can focus on how advertising on social media usage on mobile devices has impacted adolescent's behavior.

\section{ACKNOWLEDGMENTS}

This paper demonstrates that advertisements can subconsciously influence children's decision making and behavior. Parents and caregivers do play a prominent role to make children more resistant towards advertising's manipulation. External and internal processes can work hand in hand to help children to cope with persuasive information. Parents can act as guidance and forewarn children the potential manipulative information from advertisement. This paper does contain certain limitation. The longitudinal study was done only in Canada; therefore, situation in the U.S. could somewhat be different. Further research can focus on how advertising on social media usage on mobile devices has impacted adolescent's behavior. 


\section{REFERENCES}

[1] Büttner, O. B., Florack, A., \& Serfas, B. G. (2013). A Dual-Step and Dual-Process Model of Advertising Effects: Implications for Reducing the Negative Impact of Advertising on Children's Consumption Behaviour. Journal of Consumer Policy, 37(2), 161-182. https://doi.org/10.1007/s10603-0139250-0

[2] Chan, K. (2014). Advertising to children in china.

[3] Lapierre, M. A., Fleming-Milici, F., Rozendaal, E., McAlister, A. R., \& Castonguay, J. (2017). The Effect of Advertising on Children and Adolescents. Pediatrics, 140(Supplement 2), S152-S156. https://doi.org/10.1542/peds.2016-1758v

[4] Opree, S. J., Buijzen, M., \& van Reijmersdal, E. A. (2016). The impact of advertising on

children's psychological wellbeing and life satisfaction. European Journal of Marketing,

50(11), 1975-1992. https://doi.org/10.1108/EJM06-2015-0393

[5] Potvin Kent, M., \& Wanless, A. (2014). The influence of the Children's Food and Beverage Advertising Initiative: change in children's exposure to food advertising on television in Canada between 2006-2009. International Journal of Obesity, 38(4), 558-562.

[6] Rozendaal E, Buijs L and van Reijmersdal EA (2016) Strengthening Children's Advertising Defenses: The Effects of Forewarning of Commercial and Manipulative Intent. Front. Psychol. 7:1186. doi: 10.3389/fpsyg.2016.01186 